\title{
The Implementation of the NDIS: Who Wins, Who Loses?
}

\author{
Jenny Green \\ University of Technology Sydney
}

\author{
Associate Professor Jane Mears \\ University of Western Sydney
}

\begin{abstract}
The National Disability Insurance Scheme, well into its pilot phase with bipartisan support, looks clear to be the future of support for Australians with disability. This paper takes a timely review of key research and reports, analysing the potential benefits and disadvantages of the person-centred approach on which the scheme is premised. It addresses these through the frame of services, employees and people with disability in the Australian context. Whilst there are potentially overwhelming benefits there are also potentially major losses.
\end{abstract}

\section{Introduction}

The promise of the National Disability Insurance Scheme (NDIS) is that it will provide nofault insurance cover for Australians who are born with or acquire a severe or profound disability (Baker 2012, p.1). In addition to being a substantial financial commitment on the part of the Commonwealth and States, the NDIS represents a major paradigm shift in the funding models and organisation of services for those with disability that will dramatically change the planning, funding and delivery of services. This paradigm is commonly referred to as a 'person-centred' approach. Its hallmarks are user-controlled budgets and the direct purchasing of services (Dowling et al. 2006). 
Paradigm shifts are not new to disability services. Up until the middle of the Twentieth Century care was predominantly provided within the family or in government asylums and 'homes for the incurable' (Green 2010). After the Second World War, parents of children with disability began to mobilise against government institutions and build their own parentoperated services. These were funded through philanthropic fundraising and government grants (Green 2010).

In the latter part of the last century, on the back of the civil rights and women's movements, the disability rights movement started to gain momentum. People with disability started to organise for themselves both in terms of services and advocacy. 1981, the International Year of Disabled Persons was the catalyst for policy and legislative change. Disability was included in human rights and anti-discrimination legislation and the process of 'deinstitutionalisation', moving people with disability out of congregate institutional care and into the community to live and work, began in earnest (Green 2010). Service provision was distanced from parents and families who were characterised as infantilising their adult sons and daughters, and from the medical profession, which was characterised as medicalising disability as illness and aberrant. New professions emerged: disability care workers, social educators, habilitation specialists, guardians and advocates. New organisations formed with specific focuses: employment, community accommodation, leisure and recreation, rights and advocacy. People with disability mobilised and engaged (Green 2010).

In 1992 the first Commonwealth State and Territory Disability Agreement (CSTDA) was formed to streamline funding and rationalise and integrate services. The Commonwealth assumed responsibility for employment services and the States and Territories took responsibility for the rest. The premise was funding based on need and consequently the Disability Services National Minimum Data Set was established to determine need. In line with the Commonwealth, States and Territories disability human rights legislation, disability service standards were developed (Australian Institute of Health and Welfare 2014). The most recent six standards, developed in 2013, can be applied across a diverse range of circumstances (Department of Social Services 2013). They are:

- rights

- participation and inclusion

- individual outcomes 
- feedback and complaints

- $\quad$ service access

- service management.

Predominantly, government funding of service provision has gone directly to the service provider in a service-centred approach. Generally this has been in advance, in block funding agreements that defined expected outputs with a focus on cost and service quality (NSW Government 2010).

Nonetheless, there has been a small but growing shift taking place that attaches funding packages to individuals. By 2010 individual funding constituted a quarter of the funding allocated under the CSTD. On balance the individual funding was more likely to be used by people of working age with low support needs (Department of Families, Housing, Community Services and Indigenous Affairs 2010, p.13). In 2010, service providers held the majority (80 per cent) of individual packages. Financial facilitators primarily held the other twenty per cent. Currently, there are three models of decision-making. In the first, the person with disability makes the decisions and the service provider managing the finances implements the decisions. This includes decisions to change service providers, in which case the funds transfer with the individual. With the second model the service provider controls the funds, consults with the person with disability about a decision and implements that decision in the person's best interests. In the third model the funding is paid directly to the person with disability, or their substitute, to manage and purchase services as they see fit (Department of Families, Housing, Community Services and Indigenous Affairs 2010, pp.811). All three models reflect some elements of a person-centred approach.

The paradigm shift in person-centred approaches places the individual person with disability at the centre of service planning and delivery. It is variously referred to as 'direct payments' (UK), ‘self-determination’ (USA) self-managed care’ (Canada) and ‘cash for care’ (Europe) (Department of Families, Housing, Community Services and Indigenous Affairs 2010, p.7). The concept originated in North America in the late 1980s (O’Brien and Mount 1989; Mount 1992; Garner and Dietz 1996; O’Brien and O’Brien 2000). It recognises people with disability as active participants and decision makers in their lives and their communities. Support is conceived as enabling them to achieve their lifetime goals based on their strengths: 
The person-centered approach creates a team of people who know and care about the individual with a disability, who come together to develop and share a dream for the person's future, and who work together to organize and provide the supports necessary to make that dream a reality (Garner and Dietz 1996).

The Productivity Commission (2011), in its report on Disability Care and Support, described the intention of a person-centred approach as maximising 'as much as reasonably possible, the capacity for people with disabilities to take control of their lives' (Productivity Commission 2011, p.345). It takes ownership, giving choice, flexibility, control and real purchasing power to the person with disability. They can then decide what they need and want, and buy it from the provider they choose. The people with disability who purchase their services fund the disability organisations. The funds are given to the person with disability not the provider organisation.

This has been applauded as a welcome and exciting change in principle that all who are committed to the rights of people with disability embrace (Baker 2012). Nonetheless, as Hilferty and Cortis (2012, p.22) point out 'implementation is complex and this approach requires infrastructural change and strategic redesign of service delivery'. The NDIS is in a pilot phase and the process of policy development. Its final form is far from defined. Consequently, it is timely to review the research and literature that has informed State and Federal Governments with a focus on potential risks.

\section{Methodology}

The methodology used in this paper is a directed literature review to answer the research question:

What is the potential impact of the NDIS on individuals with disability, service providers and employees?

The primary sources are:

- the Product Commission's reports on the Contribution of the Not-for-profit Sector (2010) and Disability Care and Support (2011); 
- three recent Australian Community Sector Survey reports from the Australian Council of Social Services (2009, 2011, 2013); and

- four reports developed by the Social Policy Research Centre at the University of New South Wales for government and union customers (Cortis et al. 2009; Cortis et al. 2013; Department of Families, Housing, Community Services and Indigenous Affairs 2010; Hilferty \& Cortis, 2012).

Additional peer-reviewed research literature, web-based and practice literature was drawn on to provide contextual information.

\section{Findings and Discussion}

The findings and discussion are addressed together in the interests of narrative and clarity. The three stakeholder groups are taken individually, with service providers addressed first, followed by employees and then people with disability. For each stakeholder group there are specific issues which are addressed separately.

\section{Service Providers}

Person-centredness presents two types of changes for service providers. The first is conceptual and requires new and innovative ways of thinking about service provision. The second is practical, being in terms of income and cash flow. Government funding will now be directed to individuals; consequently, service providers will no longer be able to rely on block funding in advance of their service provision. Instead, service users will select services and pay on receipt of those services (NSW Government 2010, p.20). In order to get the 'conceptual' right, service providers will need to be close and sensitive to their actual and potential service users, understand the changing landscape and participate in shaping it. There is the potential for great social innovation (Productivity Commission 2010, p.xxiv). However, social innovation requires organisational capacity in the form of resources/investment and risk management, which is the 'practical'. In this section the risks and potential winners and losers are examined in relation to organisational capacity, connectedness, responsiveness and voice, and organisational roles beyond direct service delivery. 


\section{Capacity}

In terms of capacity, NFP social services are hugely reliant on government funding for their operations. In NSW alone, nearly eighty per cent of primary income is from Commonwealth and State governments (ACOSS 2011, p.29). One of the significant problems with this reliance is that most government funding does not actually cover the costs of service provision. It only covers a proportion of the costs and on average this is around seventy per cent (Productivity Commission 2010, p. 281). In the recent Australian Council of Social Services (ACOSS) community sector survey, seventy-four per cent of disability service providers reported that the cost of service delivery exceeded their revenue (ACOSS 2013, p.23). What is more, many government contracts require the return of any surplus, leaving little if any for investment in the organisation (Productivity Commission 2010, p. xxxii), let alone innovation, for person-centredness and capacity to traverse funding models from pre- to post-service delivery.

Organisational size plays a big part in capacity for innovation, traversing change and risk management. Resource reserves, cross-subsidisation, investments and loans tend to be the preserve of larger multifunctional organisations (Productivity Commission 2010, pp.225-226). The 2013 ACOSS survey found that fifty-three per cent of respondent organisations had annual revenue of less than one million dollars and eighty-three per cent had less than five million dollars (p.16). Whilst this is not directly representative of disability services, it is nonetheless indicative of a service provision sector that is disproportionately made up of small to medium players, which it is reasonable to assume are resource constrained. At face value it would seem inevitable that larger organisations will survive the funding transition better than smaller ones.

\section{Connectedness, responsiveness and voice}

Whilst larger organisations are likely to have greater capacity in the new frontier, they are also likely to have greater bureaucracy and less flexibility (Billis \& Glennerster 1998). Their governance is significantly removed from the service user/purchaser by layers of management and, in many cases, geography. What is more, disability may be only one service in a portfolio of several within an organisation. Consequently, the further up the management and governance chain information is delivered, by necessity, the more it is distilled and aggregated. 
The connection between an organisation's governance and its service users is central to the voice service users have and an organisation's responsiveness to that voice. This is particularly so in a landscape of many stakeholders such as disability services. Governance is about ends and means, what and how (Carver \& Carver 2001), the key pillars of which are mission, direction and strategy. The closer the board or governance structure is to the service user, the better and more directly informed it is likely to be, and the more likely there is to be service user representation among the board members. For example, St Vincent de Paul is a large, established, multifunctional social service that has provided disability services in NSW for many decades. It has a 17 member NSW Council. There is geographical diversity in its membership but no member identifies with a disability. Of the 17 Council Members, three have worked in disability services at some stage (St Vincent de Paul 2013, pp.12-13). By contrast, Spinal Cord Injuries Australia was established in 1966 by a group of young people with severe spinal cord injuries. It offers a range of services but with the single focus of disability. It has a nine member Board, five of whom have disability. Moreover, as part of its portfolio of disability services it engages extensively in advocacy (Spinal Cord Injuries Australia 2014). Clearly it has service user representation on its board and, for that reason alone, is better connected to its disability community than St Vincent de Paul.

It is reasonable to conclude that smaller organisations have greater connectedness with service users simply by virtue of their size, which also enables them to respond flexibly. If smaller organisations are at risk in the new person-centredness landscape then so is the strength of the voice of service users, and the strength of the connections between services users and services that goes beyond mere service delivery.

\section{Roles beyond direct service delivery}

The Productivity Commission (2010, p.xxix) identified that disability services generate benefits beyond the recipients of their services and their families. They are agents of social capital, community change and the embracing of pluralism. The most visible activity of disability organisations beyond direct service provision is advocacy. Because it is not a direct service to a service user it cannot be purchased in a new person-centred context. It is, nonetheless, an essential conduit and game changer. For example, it could be said that the National Disability Insurance Scheme is a direct result of effective advocacy on the part of the disability community. The relationship between advocacy organisations and governments has been a mixed bag. Labor governments have tended to recognise and uphold the role of 
advocacy in NFP community services and Liberal Coalition governments have tended to close it down (Green 2010, pp.40-41, Maddison 2009), the darkest times being the Howard Government years when advocacy services were defunded and confidentiality, or 'gag', clauses were included in funding contracts (Green 2010, p.40). The significance and scope of the shift in funding services under a person-centred model could see advocacy substantially reduced and left to the province of large multifunctional organisations that have the capacity to ensure their independence but may not have the detailed, nuanced agendas of smaller, community representative organisations.

The NDIS has introduced funding for a select number of organisations to operate as facilitating Disability Support Organisations. These organisations will maintain up to 20 Local Support Groups, providing and promoting local mutual support activities for people with disability (NDIS 2014). This suggests a role for small to medium organisations that is grounded in the community. Whether that role will include advocacy when it is not a direct service and, history suggests, unwanted by government, remains to be seen. Its loss would be a significant blow to civil society democracy and people with disability would be the poorer for it.

\section{Employees}

The Productivity Commission (2010, p.78) identified that labour accounts for the majority of expenditure in social services that include disability services. In 2010, the disability services workforce was estimated at approximately 68,700 workers (Martin \& Healy 2010). The roles included personal carer, home care worker, community care worker and disability and residential support worker. Seventy six per cent of the workforce was VET sector qualified with at least a Certificate III qualification (Martin \& Healy 2010). This reflects a growing professionalisation in the workforce. Along with growing professionalisation is a growing demand for career paths which are essential for workforce development, retention and stability (Productivity Commission 2010, p.269). However, currently there are three major career path impediments.

The first career path impediment is fewer training opportunities and career mobility within community services (Productivity Commission 2010, p. 263). Career paths within an organisation are largely dependent on organisational size. However, within smaller organisations there are often greater opportunities for acting in positions with a significant 
range of responsibilities. Funding staff development and training is a vexed issue for service providers. For organisations whose primary source of income is government funds there is little, if any, financial capacity for staff development and training. Alternatively, using the donor dollar for staff development and training is also problematic because of the expectation that donations are given specifically for service users (Productivity Commission 2010, p.228). What is more, a lack of career paths has been identified as a disincentive to employees investing in their own professional development and training (Productivity Commission 2010, p. 269). The intersection of this issue in organisations is staff turnover. For example, ACOSS (2011, p.26) found that in NSW the organisational turnover in disability services was fortysix per cent, whereas the average staff turnover across all service areas was twenty-six per cent.

The second career path impediment is low wages (DEEWR 2008; ACOSS 2009; Department of Families, Housing, Community Services and Indigenous Affairs 2010; Productivity Commission 2010; Kaine \& Green 2013). Whilst wages improved after the 2012 decision by Fair Work Australia in the Social and Community Services (SACS) equal remuneration order, they are still low relative to other industries. In April 2014 on www.mycareer.com.au , Disability Support Worker positions were advertised requesting the following common knowledge and experiences:

- Experience supporting people with a disability.

- Experience working with people with autism/acquired brain injury/psychiatric disability who may display challenging behaviours.

- Experience providing direct personal care.

- Good communication and computer skills.

- $\quad$ Cert III or IV in disabilities is an advantage.

- A current first aid certificate.

- Respect for the rights and dignity of all people from all backgrounds in the community.

- Local community knowledge and connections. (My Career 2014)

The requested complex knowledge and experiences required of care workers not only reflect the growing professionalisation of the work but also the increasing requirement for disability service workers to deal with more complex and diverse client needs, an issue identified by the 
Productivity Commission (Productivity Commission 2010, p. 263). Nonetheless, hourly rates ranged from twenty dollars to thirty dollars per hour.

The third career path impediment is the significant and increasing casualisation of the workforce. This has been a long-standing issue (Martin \& King 2008). For example, the Australian Bureau of Statistics reported in 2009 that sixty-eight per cent of community service workers were part-time or casual, compared to twenty-nine per cent of the workforce overall. This figure does not reflect employee choice. The Productivity Commission (2009, p.264) reported that thirty percent of part-time workers were part-time because that was the only work offered to them and that a substantial proportion of workers reported a desire for more work (Cortis et al. 2009; Martin \& King 2008; Productivity Commission 2010, p.264). A casual workforce gives greater flexibility and economy to the employer with little or no costs attached to cancelling and rearranging shifts. Consequently, greater casualisation of the workforce under the NDIS and person-centred care has been foreshadowed as a major issue of concern (Hilferty \& Cortis 2012; Productivity Commission 2010). The staffing risks attached to person-centred care and direct purchasing by service users are intermittent service usage, short notice requests or cancellations of care (Baxter et al. 2010) and service user 'churn' as purchasers pick and choose to find the right care.

In the UK, where person-centred care is already under way, policy makers are concerned that, whilst a casualised workforce enables providers to manage fluctuating demands, it may also result in reduced training and service quality (Cunningham \& Nickson 2010). Clearly this is an issue for service users, but it is also an issue for employees who, by and large, choose to work in community services for lower wages because they believe they are making a contribution to the social benefit and this is meaningful and important to them (Productivity Commission 2010, p.7; Green 2010).

How does the future look then for employees under the NDIS and person-centred care? Predictions would suggest that there will be greater casualisation at the frontline and less inhouse training and development due to the uncertain return on investment given the likely fluctuations in service demand. This will enlarge an already existing career hurdle to first line management, making the path from entry level difficult and, consequently, unattractive. Again, larger organisations with greater resource capacity will most likely offer the clearer career paths and thus be more attractive to the committed and career-minded workers. 


\section{Front-line employment}

In terms of possible front-line employment options there is potential for three tiers of direct care work. One tier may be occupied primarily by for-profit providers and offer more expensive and ostensibly better quality care for those people who can afford to supplement their NDIS payments. Another tier may be predominantly occupied by not-for-profit providers and offer a 'no frills' service for those paying the nominated rate under the NDIS. The third tier may be direct employment by the service user or their families and have little or no employee benefits, such as health and safety, paid training and professional supervision (Carmichael \& Brown 2002, p.803; Productivity Commission 2010).

This raises the question of the quality of the services provided and what that means for service users. Studies in the UK link good quality services and service user satisfaction with good employee working conditions that include training, guaranteed working hours, equitable remuneration and tenure within an organisation exceeding five years (Netten et al. 2007, p.84). By the same token, the Productivity Commission (2010, p.263) found that poorly trained, inexperienced and unqualified staff had adverse effects on service users, with poor quality care at best and negligence at worst.

\section{People with Disability}

If a person with disability or their guardian is well informed or well supported, able to exercise agency and has options for choice, then person-centredness has few risks and offers considerable benefits. LEAD Barwon, a project located in the NDIS launch site of Geelong, is documenting such stories and there is little doubt about the life-changing capacity of person-centredness with options including home modifications, equipment, tailored care and support, and therapy and tutoring at home (LEAD Barwon 2014). Nonetheless, it is not without its challenges. Reports from the UK identify that for people with disability, taking on the role of employer for direct support workers can be a steep learning curve, is time consuming and can include additional costs and risks, such as cash flow and insurance (Adams \& Godwin 2008; Carmichael \& Brown 2002; Glendinning et al. 2000). In a Victorian trial the people with disability who chose to employ direct support workers already had relevant experience, such as bookkeeping, accounting, or business ownership, that 
assisted them in executing their role (HDG Consulting 2010, p.25). This suggests that, for most people with disability, some support to operate as an employer is desirable.

The main risks with person-centredness arise for individuals with disability who have little or no agency. Their choices will need to be made and managed by others such as families, guardians and organisations. Inherent in this is the potential for exploitation (Productivity Commission 2010, p.321; Department of Families, Housing, Community Services and Indigenous Affairs 2010, p.32). Unscrupulous service providers, for example, could over service and 'cherry pick' users who have the greatest capacity to pay or who are the least expensive to support (Productivity Commission 2010, p.324).

Another difficult or risky area is the employment of family members or close family friends in direct support. There may be good reasons for considering employing family members, such as their detailed and intimate knowledge of the person with disability and the comfort and trust between them. Nonetheless, the downside can be a blurring of roles, conflicts of interest, burnout, limited if any quality control and a compromised independent voice. All or any of these issues may increase the vulnerability of the person with disability (Disability Services Commission 2012, p.3).

Finally, moving people with high support needs, particularly cognitive and communication impairments, from long term placements, possibly through a number of services, to find the one that best fits can incur losses often overlooked (Green \& Wunsch 1994). Whilst there is little doubt that obvious information such as skill levels, support needs, and medical and dental records will move with the individual, more nuanced information such as preferences, interests, friendships, connections, routines, likes and dislikes may not; not to mention essential factors that contribute to identity such as a sense of belonging. Moreover, this information can be valued quite differently by family members and discounted as unimportant. Its loss can have a significant and sustained impact on a person's quality of life (Green \& Wunsch 1994). It underscores the importance of ensuring informed, careful and considered decision-making, a process that may require multiple inputs and support.

\section{Conclusion}

The promise of the NDIS is that it will enable all Australians with disability to live full, engaged and rich lives of their choice. Many hopes and dreams are invested in this scheme 
and, indeed, many hours of tireless work have been invested to bring this dream to fruition. However, all of the reports reviewed for this paper highlighted, alongside the positive experiences of those already receiving individual support packages, that there is much confusion, misunderstanding and anxiety from providers, employees and people with disability. Implementation will inevitably be complex.

As stated at the outset, the philosophy and principles of person-centredness and the NDIS are not in question here. The purpose of the paper is to draw attention to the possible risks and losses so that we can minimise these risks and not lose effective programs and experienced and committed workers. A major concern, as outlined above, is the potential drying up of funding for the specialist support organisations that are providers of information to, and advocates on behalf of, those with disability and their carers. Loss of these organisations, and the knowledge and human capital within, could be devastating to the disability human rights movement. Precautions can be taken in this planning and pilot phase.

We all need to be as well informed as possible as to unintended risks and losses. Cortis et al. (2013, p.43) summarise a way forward to take account of the interests of organisations, employees and people with disability. It is referred to as the 'high road' strategy (Folbre 2006) and requires higher costs and investment in the short term to support organisations and individuals through the transition and establishment of person-centredness. Implemented effectively, it will lead to more sustainable and higher quality service delivery in the immediate and longer terms with 'better outcomes for people with disabilities, and a more efficient and cost-effective system of care' (Cortis et al. 2013, p.43). We need to follow this high road.

\section{References}

Australia, Department of Families, Housing, Community Services and Indigenous Affairs 2010, Occasional Paper no. 29: Effectiveness of individual funding approaches for disability support, Accessed 15 April 2014 http://www.dss.gov.au/sites/default/files/documents/05 2012/op29.pdf

Australia, Department of Social Services 2013, National Standards for Disability Services, Accessed 15 April 2014 http://www.dss.gov.au/sites/default/files/documents/12 2013/national standards for disabilit y_services_-_full_standards_2.pdf

National Disability Insurance Scheme 2014, Disability Support Organisations - Capacity Building Strategy Grants, Accessed 15 April 2014, http://www.ndis.gov.au/document/759 
Australian Council of Social Services 2013, ACOSS Australian Community Sector Survey 2013. Accessed 15 April 2014

http://www.acoss.org.au/images/uploads/Australian_Community_Sector_Survey_2013_ACO $\underline{\text { SS.pdf }}$

Australian Council of Social Services 2011, Australian Community Sector Survey 2011 - VOLUME III - NSW Accessed 15 April 2014 http://acoss.org.au/images/uploads/ACSS_Report_Volume_3_New_South_Wales.pdf

Australian Council of Social Services 2009, Australian Community Sector Survey 2009 - VOLUME I - National Accessed 15 April 2014 http://www.acoss.org.au/upload/publications/papers/5961_CSS combined report final.pdf

Adams, L., \& Godwin, L. 2008, Employment Aspects and Workforce Implications of Direct Payments, IFF Research, London.

Australian Institute of Health and Welfare 2014, Disability support services: Services provided under the National Disability Agreement 2012-13, Bulletin 122, July 2014, Accessed 15 April 2014 http://www.aihw.gov.au/WorkArea/DownloadAsset.aspx?id=60129547852

Baker, A. 2012, The New Leviathan: A National Disability Insurance Scheme, CIS Policy Monograph 131.

Billis, D. \& Glennerster, H. 1998, 'Human services and the voluntary sector: Towards a theory of comparative advantage', Journal of Social Policy, vol. 27, no.1, pp. 79-98. doi: http://dx.doi.org/10.1017/S0047279497005175

Carmichael, A. \& Brown, L. 2002, 'The future challenge for direct payments', Disability \& Society, vol. 17, no. 7, pp. 797-808. doi: http://dx.doi.org/10.1080/0968759022000039082

Carver, J. \& Carver, M. 2001, 'Le modèle Policy Governance et les organismes sans but lucratif (Carver's Policy Governance ${ }^{\circledR}$ Model in Nonprofit Organizations)' Gouvernance - revue internationale, vol. 2, no. 1 pp. 30-48, Accessed 20 April 2014 http://www.carvergovernance.com/pg-np.htm

Cortis, N., Hilferty, F., Chan, S. \& Tannous, K. 2009, Labour Dynamics and the Non-Government Community Services Workforce in NSW, SPRC Report 08/09, Report prepared for the NSW Department of Premier and Cabinet and the Department of Community Services, University of New South Wales, May 2009.

Cortis, N., Meagher, G., Chan, S., Davidson, B., \& Fattore, T. 2013, Building an Industry of Choice: Service Quality, Workforce Capacity and Consumer-Centred Funding in Disability Care, Final Report prepared for United Voice, Australian Services Union, and Health and Community Services Union, Social Policy Research Centre, University of New South Wales, Sydney.

Disability Services Commission 2012, Family Members as Paid Support Workers Policy, Western Australian Government, Perth.

Dowling, S., Manthorpe, J., Cowley, S., King, S., Raymond, V., Perez, W. \& Weinstein, P. 2006, Person-centred Planning in Social Care: A Scoping Review. Joseph Rowntree Foundation, King's College, London.

Folbre, N. 2006, 'Demanding quality: Worker/consumer coalitions and "high road" strategies in the care sector,' Politics and Society, vol. 34, no. 1, pp. 1-21. doi: http://dx.doi.org/10.1177/0032329205284754

Garner, H. \& Dietz, L. 1996, 'Person-centered planning: maps and paths to the future', Four Runner, vol. 11, no. 5, pp. 1-2.

Glendinning, C., Halliwell, S., Jacobs, S., Rummery, K., \& Tyrer, J. 2000, 'New kinds of care, new kinds of relationships: how purchasing services affects relationships in giving and receiving personal assistance', Health \& Social Care in the Community, vol. 8, no. 3, pp. 201-211. doi: http://dx.doi.org/10.1046/j.1365-2524.2000.00242.x

Green, J. 2010, The Business of Values and Value of Business: The role of organisational values in the recruitment and selection of nonprofit community service managers and executives. $\mathrm{PhD}$ Thesis, University of Technology, Sydney. Accessed 15 April 2014 http://epress.lib.uts.edu.au/research/bitstream/handle/2100/1206/01Front.pdf?sequence=1 
Green, J. \& Wunsch, A. 1994, 'The Lives of Six Women', Interaction, the Journal of The National Council on Intellectual Disability, vol. 7, no. 4, pp. 11 - 15.

HDG Consulting 2010, Evaluation of Direct Employment Project Melbourne, HDG Consulting Group.

Hilferty, F. and Cortis, N. 2012, Analysis of Workforce Indicators Suitable for the Ageing, Disability and Home Care Sectors, Social Policy Research Centre, Report 5/12. Accessed 15 April 2014 https://www.sprc.unsw.edu.au/media/SPRCFile/2012 5 Workforce Indicators for Ageing Disability_and_Home_Care_Final_Report_with_ADHC_Comments_Aug_11_FINAL_v2.p $\underline{\mathrm{df}}$

Kaine, S. \& Green, J. 2013, 'Outing the silent partner: Espousing the economic values that operate in not-for-profit organizations', Journal of Business Ethics, vol.118, no. 1, pp. 215-225. doi: http://dx.doi.org/10.1007/s10551-012-1583-0

Lead Barwon 2014, Accessed 20 April 2014 http://kerrynlestersmith.wordpress.com

Maddison, S. 2009, 'Lessons to be learned: Reviving advocacy organisations after the neo-con men', Cosmopolitan Civil Societies Journal, vol.1, no. 2, pp. 18-29.

Martin, B. and King, D. 2008, Who cares for Older Australians - A picture of the Residential and Community based Aged Care Workforce, 2007, National Institute of Labour Studies, Flinders University, Adelaide.

Martin, B. \& Healy, J. 2010, Who Works in Community Services. A profile of Australian workforces in child protection juvenile justice, disability services and general community services, National Institute of Labour Studies, Flinders University, Adelaide.

Mount, B. 1992, Person-Centered Planning: Finding directions for change using personal futures planning, Graphics Futures, Inc., New York.

My Career 2014, Disability Services Australia, Support Worker, Accessed 20 April 2014 http://mycareer.com.au/jobs/wollongong-illawarra-area-nsw/community/communityservices/9254320-support-worker.aspx?RefineUrl=\%2f2145116\%2fjobs\%2f

NSW Government 2010, Stronger Together: A new direction for disability services in NSW 20062016. The next phase 2011-2016, Accessed 15 April 2014 http://www.facs.nsw.gov.au/_data/assets/pdf_file/0010/236359/898_StrongerTogether_2.pdf

O’Brien, C. and O'Brien, J. 2000, The Origins of Person-Centered Planning, A Community of Practice Perspective, Responsive Systems Associates.

O’Brien, J. and Mount, B. 1989, Telling New Stories, The Search for Capacity Among People with Severe Handicaps, Responsive Systems Associates, available from the Center on Human Policy, Law and Disability Studies, Syracuse University, Accessed 15 April 2014 http://thechp.syr.edu/index.html.

Productivity Commission 2010, Contribution of the Not-for-Profit Sector, Research Report, Canberra, Accessed 15 April 2014 http://www.pc.gov.au/__data/assets/pdf_file/0003/94548/not-forprofit-report.pdf

Productivity Commission 2011, Disability Care and Support, Report no. 54, Canberra, Accessed 15 April 2014 http://www.pc.gov.au/projects/inquiry/disability-support/report

Spinal Cord Injuries Australia 2014, Board of Directors, Accessed 20 April 2014 https://scia.org.au/board-of-directors

Spinal Cord Injuries Australia 2014, Policy and Advocacy, Accessed 20 April 2014 https://scia.org.au/policy-and-advocacy

St Vincent de Paul Society NSW 2013, Annual Report 2012/13, Accessed 20 April 2014 http://www.vinnies.org.au/icms_docs/175467_Annual_Report_2012_-_2013.pdf 